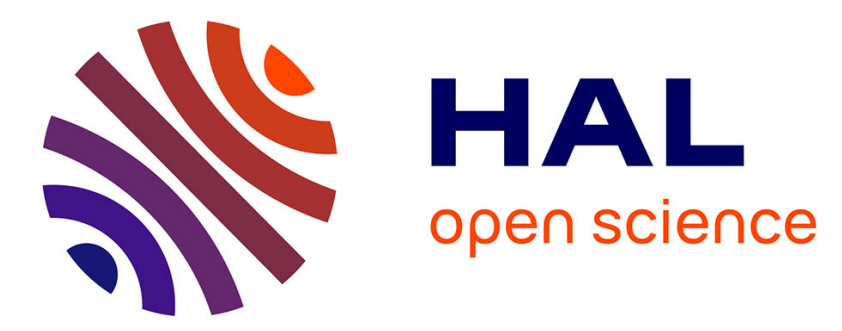

\title{
Dependence on the Chromium Content of the High-Temperature Oxidation Behavior of Ta-Rich Nickel-Based Cast Alloys \\ Patrice Berthod, Zohra Himeur
}

\section{- To cite this version:}

Patrice Berthod, Zohra Himeur. Dependence on the Chromium Content of the High-Temperature Oxidation Behavior of Ta-Rich Nickel-Based Cast Alloys. Oxidation of Metals, 2018, 90 (1-2), pp.135151. 10.1007/s11085-017-9828-z . hal-02186062

\section{HAL Id: hal-02186062 \\ https://hal.science/hal-02186062}

Submitted on 17 Jul 2019

HAL is a multi-disciplinary open access archive for the deposit and dissemination of scientific research documents, whether they are published or not. The documents may come from teaching and research institutions in France or abroad, or from public or private research centers.
L'archive ouverte pluridisciplinaire HAL, est destinée au dépôt et à la diffusion de documents scientifiques de niveau recherche, publiés ou non, émanant des établissements d'enseignement et de recherche français ou étrangers, des laboratoires publics ou privés. 


\title{
Dependence on the chromium content of the high temperature oxidation behavior of Ta-rich nickel-based cast alloys
}

\author{
Patrice Berthod ${ }^{1,2}$, Zohra Himeur $^{1}$ \\ ${ }^{1}$ Faculty of Science and Technologies \\ ${ }^{2}$ CNRS, Institut Jean Lamour (UMR 7198), Department CP2S \\ ${ }^{1,2}$ University of Lorraine, Postal Box 70239, 54506 Vandoeuvre-lès-Nancy, FRANCE \\ himeurzahra@gmail.com,patrice.berthod@centraliens-lille.org \\ Corresponding author: patrice.berthod@centraliens-lille.org
}

\begin{abstract}
The high-temperature stability of the primary tantalum carbides is a problem of importance for chromium-rich cast alloys, based on cobalt or nickel. The focus of this study was nickel-based alloys, as these alloys are particularly sensitive to a lack of TaC carbides in the ascast state and by dissolution due to high-temperature exposure. In this work, a possible way for promoting the formation of many $\mathrm{TaC}$ carbides by changing from the usual $30 \mathrm{wt} . \%$ chromium content was investigated. Five alloys with $\mathrm{Cr}$ content varying from 10 to $50 \mathrm{wt} . \%$ were prepared and then subjected to microstructure characterization and to oxidation tests. In contrast with what was expected, decreasing the $\mathrm{Cr}$ content in comparison to the Ni-30Cr-0.4-6Ta reference alloy did not succeed in obtaining more $\mathrm{TaC}$ carbides, but instead had the opposite effect. Concerning the high-temperature oxidation behavior at 1127 and $1237^{\circ} \mathrm{C}$, loss of resistance was observed only for a $\mathrm{Cr}$ content at the lower level of $10 \mathrm{wt} . \%$. It was noticed that a subscale $\mathrm{CrTaO}_{4}$ developed during oxidation and seemed to promote oxide spallation during cooling.
\end{abstract}

Keywords: Cast nickel-based alloys; High tantalum content; Varying chromium content; High temperature oxidation

Post-print version of the article Oxid Met (2018) 90:135-151; https://doi.org/10.1007/s11085-017-9828-z

\section{INTRODUCTION}

Chromium is, with aluminum and silicon, one of the three main elements added in rather high quantities in superalloys to allow them resisting oxidation by hot gases in service [1,2]. In presence of carbon chromium may also play the role of a carbide-former element. In favorable chemical compositions, it allows obtaining $\mathrm{Cr}_{7} \mathrm{C}_{3}$ or $\mathrm{Cr}_{23} \mathrm{C}_{6}$, the types of chromium carbides which are usually met in superalloys [3,4]. It is commonly considered that $20 \mathrm{wt} . \% \mathrm{Cr}$ is the low limit for a nickel-based alloy for keeping a chromia-forming behavior on long time when it is exposed at high temperature in oxidant atmosphere $[1,2,5]$. However chromium may present several disadvantages. One already knows the toxicity problems of the $\mathrm{Cr}^{\mathrm{VI}}$ specie [6] and the possible re-oxidation of the protective chromia scale into gaseous species $[2,7,8]$, notably in 
presence of water vapor $[9,13]$. But also the presence of chromium in nickel alloys may threaten the thermodynamic stability of the tantalum carbides [14]. This may be a problem since these ones play an important role in the reinforcement of cast superalloys [15], notably in the case of the cobalt-based ones [16]. Indeed, in contrast with some other MC carbides in nickel alloys (e.g. HfC) [17], or with all MC carbides in cobalt-based or iron-based alloys [18, 19], it seems that tantalum carbides exist together with chromium carbides. This is true even for the nickel alloys which are designed to promote the formation of exclusively $\mathrm{TaC}$, i.e. containing as carbon atoms as tantalum atoms. It is maybe possible to favor the development of more $\mathrm{TaC}$ in a nickelchromium alloy by decreasing its chromium content in order to lower the efficiency of this carbide-former competitor. But this needs to be experimentally verified as well as the consequences of this $\mathrm{Cr}$ decrease for the behavior of the alloy in oxidation at high temperature. One can fear threats on the oxidation resistance as soon as the $\mathrm{Cr}$ content becomes lower than a limit. This limit may perhaps depend on the presence of the significant quantity of tantalum required to obtain $\mathrm{TaC}$ volume fractions high enough to achieve efficient mechanical strengthening in case of a success of their stabilization by $\mathrm{Cr}$ impoverishment.

In this work one examines, for a series of $\{\mathrm{Ni}-0.4 \mathrm{C}-6 \mathrm{Ta}$, wt. $\%\}$-based alloys, the evolution of the carbides population when the $\mathrm{Cr}$ content decreases from the classical $30 \mathrm{wt} \%$ value down to 0 . One also investigates the consequences of these changes in chromium content on the oxidation behavior at two temperatures which are higher than $1100^{\circ} \mathrm{C}$. This study was also extended to alloys with $\mathrm{Cr}$ contents beyond $30 \mathrm{wt} . \%$, up to $50 \mathrm{wt} . \%$, since it appeared also interesting to explore also the natures of the carbides and the oxidation behavior when the opposite action is done.

\section{EXPERIMENTAL}

\section{Elaboration of the alloys}

A series of five Ni-based alloys was synthesized by induction melting and casting under inert atmosphere. All these alloys contain $0.4 \mathrm{wt} . \% \mathrm{C}, 6 \mathrm{wt} . \% \mathrm{Ta}$ and a variable $\mathrm{Cr}$ content. These alloys are different from one another about their chromium content. The $\mathrm{Cr}$ content varies from 10 to 50 wt.\%. The studied alloys are named "NTCxCr", in which $\mathrm{x}$ is the weight content in Cr. Their targeted chemical compositions are shown in Table 1. For each alloy a mix of metallic elements (Ni, Cr, Ta: Alfa Aesar, C: pure graphite) was prepared by targeting a total mass of about 40 grams. This mix of pure elements was placed in the water-cooled copper crucible of a CELES (France) furnace. This crucible was surrounded by a silica tube to isolate from air the inert internal atmosphere (300 millibars of pure Ar). The mixed elements were heated until reaching $2.5 \mathrm{kV}$. This voltage was maintained during 30 seconds (thermal homogenization). Voltage was then increased until reaching $5 \mathrm{kV}$. It was maintained 3 minutes for achieving total melting then chemical homogenization. The alloy solidified a first time by decreasing the injected power. It was thereafter melted again according to the same cycle, in order to be sure of the total absence of any not-molten parts in the final ingot.

\section{Preparation of the samples, oxidation tests in furnace and metallographic preparation}

The obtained ingots were of a compact conic shape. Each of them was divided into four quarters, by using a Buehler Delta Abrasimet metallographic saw. One of these quarters was prepared as a metallographic sample devoted to the control of the as-cast microstructure. Two 
others were prepared for the high temperature oxidation tests. These ones were ground all around using 1200-grit SiC papers. A quarter by alloy was exposed at $1127^{\circ} \mathrm{C}$ in a resistive furnace (Nabertherm) during 24 hours. A second one was exposed at $1237^{\circ} \mathrm{C}$, in the same furnace and in the same atmosphere (laboratory air). After total cooling the oxidized samples were all coated by cathodic pulverization of gold. This aimed to give a good electrical conductivity to their surface, despite the presence of the oxide scales. A second coating was then electrolytically applied $\left(\mathrm{Ni}^{2+}\right.$ solution heated at $50^{\circ} \mathrm{C}, 2$ hours at about $20 \mathrm{~mA} / \mathrm{cm}^{2}$ ). This led to a sufficiently thick shell of electrolytic $\mathrm{Ni}$ for protecting the external oxide scales during cutting. The oxidized samples were thereafter cut in two parts, by using the same metallographic saw as described above. The as-cast parts and the parts of oxidized samples were embedded in a cold resin mixture (ESCIL, France). They were ground with $\mathrm{SiC}$ papers from 240-grit to 1200-grit, water-washed and ultrasonically cleaned. Final polishing was achieved with a $\{1 \mu \mathrm{m}$ hard particles $\}$-containing textile disk. The obtained mirror-like samples were thus ready for metallographic characterization.

\section{Bulk, subsurface and surface characterization}

A JSM-6010LA Scanning Electron Microscope (SEM) from JEOL (Japan), equipped with an Energy Dispersion Spectrometer (EDS), was used to visualize the as-cast microstructures. Micrographs were taken in Back Scattered Electrons mode (BSE) to carry out surface fraction measurements of the different types of carbides present in the bulk. These measurements were done using the image analysis tool of the Photoshop CS software of Adobe. The subsurface microstructure changes due to oxidation were also observed using the SEM in BSE mode, as well as the oxides formed internally and externally. The depths of the subsurface alloy zones which lost their carbides (from the alloy/external oxide interface), were measured. It was also attempted to value the average thickness of the external oxides. Spot EDS analyses were carried out to assess the chemical compositions in the subsurface (concentration profiles), notably in the extreme surface close to the oxidation front. Spot EDS analyses also allowed identifying the nature of all the present oxides.

\section{RESULTS}

\section{Microstructures of the obtained alloys}

The five micrographs presented in Figure 1 were taken using the SEM in BSE mode. They illustrate the as-cast microstructures of the alloys. The obtained chemical compositions are displayed in Table 2. Concerning the later one it can be seen that the $\mathrm{Cr}$ content is rather well respected for all alloys. This seems to be not the case for tantalum. Indeed, instead to be diminished by possible oxidation during the elaboration as this can be feared by considering the high reactivity of this element, its content appears to be higher than expected. This curious phenomenon is classically met when the global chemical composition of a TaC-rich alloy is assessed by EDS: the TaC carbides emerging on the metallographic surface lead to the enhancement of the concentration in Ta. This phenomenon did not occur for the NTC10Cr alloy (and may be for the NTC20Cr one too). This one obviously contains much less TaC carbides than the other alloys.

About the microstructures one can remark first that the matrix is unsurprisingly dendritic in all cases. Two types of particles are present: chromium carbides (the dark ones) and tantalum 
carbides (the white ones). The microstructure of the NCT30Cr alloy is rather well-known. Indeed the $\mathrm{Ni}$ (bal.)-30Cr-0.4C-6Ta alloy (contents in wt.\%) was many times characterized earlier (e.g. in [14]). One can easily recognize the $\mathrm{Cr}_{7} \mathrm{C}_{3}$ and $\mathrm{TaC}$ carbides, notably. Thus, thanks to the aspect similarities (morphology, tint), the dark particles and the white ones appearing in the NTC10Cr, NTC20Cr and NTC40Cr alloys, can be identified as being $\mathrm{Cr}_{7} \mathrm{C}_{3}$ and $\mathrm{TaC}$, respectively. In the first four alloys, one can also see that the peripheries of dendrites are particularly clear. This is due to tantalum segregation during solidification. This phenomenon, classical for such alloys, well helps to distinguish the dendritic structure of the matrix of the NTC10Cr alloy. The NTC50Cr alloy is particular since very dark areas coexist with the dendritic matrix and white areas. These white areas are composed of dendrites peripheries rich in Ta (due to Ta segregation) and of tantalum carbides. The very dark areas are certainly the BCC Cr-based rich part of the matrix which was previously identified in a $\{\mathrm{Ta}, \mathrm{C}\}$-free $\mathrm{Ni}-50 \mathrm{Cr}$ alloy [22] whose matrix structure is very similar to the NCT50Cr one. This can be verified, for the chemical composition point of view, in the Table 3 which gives the results of EDS spot analysis of the two phases (last lines). According to these results, the grey dendrite centers contain more $\mathrm{Ni}$ than $\mathrm{Cr}(45-46 \mathrm{wt}$ \% $\mathrm{Cr}$ only) while the dark areas contain $60 \mathrm{wt} . \% \mathrm{Cr}$ and more.

In the top part of each micrograph presented in Figure 1 one also gives the values of the surface fractions of the chromium carbides and of the tantalum carbides, except for the NCT50Cr alloy in which it was not possible to distinguish the tantalum carbides from the highly Tasegregated peripheral zones of dendrites. These values are the average values and the standard deviation values calculated from three image analyses. One can see that the surface fraction of chromium carbides increases from the NCT10Cr alloy to the NCT20Cr one. It decreases when arriving to the NCT30Cr. It increases again for the NCT40Cr alloy and decreases again for the NCT50Cr alloy. At the same time, the surface fraction increases steadily from the NCT10Cr alloy to the NCT30Cr alloy and decreases when the $\mathrm{Cr}$ content keeps on increasing.

Detailed views of the microstructures of the five alloys after elaboration are given in Figure 2. One can first observe the carbides in better condition. This allows discovering the eutectic origin of the chromium carbides: these ones are acicular and mixed with the peripheral parts of the matrix dendrites (NTC10Cr to NTC40Cr). The tantalum carbides are obviously also of a eutectic nature: script-like shaped and mixed with the outer part of the dendrites too (NTC10Cr to NTC30Cr). The white Ta-rich particles present in the interdendritic areas of the NTC40Cr alloy seem to be morphologically different from the eutectic $\mathrm{TaC}$ of the alloys which contain less chromium: they appear to be intermediate to the well-defined script-like shaped TaC (alloys with $\mathrm{Cr} \leq 30 \mathrm{wt} . \%)$ and the more diffuse white interdendritic particles present in the NTC50Cr alloy. The spot analyses performed on the coarsest carbides found in the alloys seemed confirming the stoichiometries of the $\mathrm{Cr}_{7} \mathrm{C}_{3}$ carbides (NTC10Cr to NTC40Cr) and of the $\mathrm{TaC}$ ones (NTC10Cr to NTC50Cr). In contrast, no concluding result was obtained by this way for the Ta-rich white areas which are present in the NCT50Cr alloy, except the fact that it seems to be very rich in Ta.

\section{Oxidation result at $1127^{\circ} \mathrm{C}$}

After $24 \mathrm{~h}$ spent at $1127^{\circ} \mathrm{C}$ in the laboratory air, more or less complex oxide scales were present around the samples. Except for the two Cr-poorest alloys (NCT10Cr and NCT20Cr) the external scale spalled off during the cooling. It was thus not always possible to extensively specify all the oxidation products. General views of the surface and subsurface deterioration seen 
in cross-section are provided in Figure 3 while more magnified micrographs can be consulted in Figure 4. The NCT10Cr alloy was obviously covered by a mix of rather thin chromia (constituting the inner layer) and by a thicker complex oxide involving both nickel and chromium (constituting the outer layer). The alloy/external scale is very irregular. This suggests that oxidation was penetrating, and that catastrophic oxidation was imminent. In the subsurface, but very close to the alloy/oxide scale interface, an almost continuous and rather compact complex oxide involving both chromium and tantalum was present. As soon as the chromium content in alloy is equal to $10 \mathrm{wt} . \% \mathrm{Cr}$ or higher, only chromia is present on the surface of the alloy. Chromia is very present over the NCT20Cr but just small chromia parts remain on surface for the NCT30Cr, NCT40Cr and NCT50Cr alloys. Just below, in the extreme surface part of alloy, the $\mathrm{CrTaO}_{4}$ oxide is present in significant quantity, but more as juxtaposed oxides islands than an almost continuous subscale as for the NCT10Cr alloy. One can also notice that, when the $\mathrm{Cr}$ content in alloy increases along this series, additional $\mathrm{CrTaO}_{4}$ oxides become to be also present in the whole carbide-free zone (NCT40Cr and NCT50Cr). In contrast they only constitute the outer almost continuous oxide at the extreme surface of alloy for the NCT10Cr, NCT20Cr and NCT30Cr alloys. One must say that, in the case of the NCT50Cr alloy, the outer alloy zone modified by oxidation is more a $\{\mathrm{BCC} \mathrm{Cr}$-based phase $\}$-free zone than a carbide-free zone as all the other alloys.

Obviously, the running development of a zone which is free of carbides (all alloys except NCT50Cr) or which is free of BCC Cr-based phase (NCT50Cr), demonstrates the diffusion of Cr and Ta toward the oxidation front (Figure 5). SEM/EDS concentration profiles acquired perpendicularly to the oxidation front confirm that $\mathrm{Cr}$ diffusion and Ta diffusion occurred. These $\{\mathrm{Cr}$ and $\mathrm{Ta}\}$-depleted depths tend to be deeper than the carbide-free zones but the depths are of the same order of magnitude. The depth of the carbide-free zone depends on the alloy, as is to say on the initial alloy chromium content. It decreases from about $70 \mu \mathrm{m}$ for NCT10Cr to about $40 \mu \mathrm{m}$ for NCT30Cr. It increases to $60 \mu \mathrm{m}$ for NCT40Cr. In the case of NCT50Cr the depth does not keep on increasing but it decreases, on the contrary. One must notice, for the later alloy, that what is significantly changed in the subsurface is not due to carbide dissolution but to the disappearance of the second phase of matrix (the BCC Cr-based one).

Table 4 also shows few values of thickness of the external oxide scale. Measurement was possible only for the NCT10Cr and NCT20Cr alloys. These ones kept oxide scale parts in quantities high enough to permit thickness evaluation, in contrast with the other alloys which all lost their external oxide scales by spallation at cooling. Since the oxidation process was rather heterogeneous all along each surface, with as results very variable nature and thickness, only a tentative range of thickness is given. Oxidation induced $\mathrm{Cr}$ and $\mathrm{Ta}$ depletion for all alloys (examples in Figure 5). The chromium content in extreme surface was assessed by three EDS spot analyses. The results (average \pm standard deviation) are given in Table 5. For each alloy the decrease in $\mathrm{Cr}$ content close to the alloy/external oxides interface was between 5 and $10 \mathrm{wt} . \%$. The local loss in $\mathrm{Cr}$ content continuously increases from the NCT20Cr alloy to the NCT50Cr alloy. The NCT10Cr does not obey this evolution because of its almost catastrophic oxidation.

\section{Oxidation result at $1237^{\circ} \mathrm{C}$}

The metallographic exploitation of the samples oxidized at $1237^{\circ} \mathrm{C}$ for the same duration of 24 hours was driven similarly to the oxidation tests at $1127^{\circ} \mathrm{C}$, by: 
- the observation of the cross-sections at $\times 250$ (Figure 6) and $\times 1000$ (Figure 7),

- performing concentration profiles in the subsurface perpendicularly to the oxidation front (Figure 5, graphs of the right side),

- the tentative measurement of the external oxide scale thickness (Table 6) when limited spallation at cooling did allow that,

- the measurement of the carbide-free depth (Table 6)

- and the measurement of the chromium content in extreme surface (Table 7).

The results and observations were globally the same as for the samples oxidized at $1127^{\circ} \mathrm{C}$ : start of catastrophic oxidation for the Cr-lowest alloy (NCT10Cr), local high thickness of the external scale, very irregular alloy/scale frontier, presence of many types of oxides, minimum of carbide-free depth for the NCT30Cr alloy, existence of a $\{\mathrm{BCC}$ Cr-phase $\}$-free subsurface for the NCT50Cr alloy, same type of evolution of the Cr-loss in extreme surface from the NCT10Cr alloy to the NCT50Cr one, and same types of $\mathrm{Cr}$ and Ta concentration profiles.

Thus the differences between the two temperatures are not qualitative, but they are quantitative: thicker external oxide scales and deeper carbide-free (or BCC Cr phase-free) zones. The chromium contents in extreme surface do not depend on temperature for a given alloy (Figure 8), the better $\mathrm{Cr}$ diffusion easiness offsetting the higher $\mathrm{Cr}$ consumption.

\section{DISCUSSION}

Concerning the effect of the modification of the $\mathrm{Cr}$ content on the natures and proportions of the obtained carbides in cast alloys, looking to the SEM/BSE micrographs allowed first feeling that the variation of the chromium content in the chemical composition of the alloys had consequences on the carbides population of the as-cast alloys. Image analysis allowed confirming these trends by quantitative results. The lowest $\mathrm{Cr}$ content tested here, $10 \mathrm{wt}$.\% Cr, led to a lowering of the chromium carbides quantity but curiously also of the tantalum carbides one. Adding 10wt.\%Cr more induced a logical increase in chromium carbides but also in tantalum carbides. Repeating this addition to reach $30 \mathrm{wt} . \% \mathrm{Cr}$ led to a maximal fraction in TaC carbides and to the rarefaction of the chromium carbides. Choosing a $40 \mathrm{wt} . \% \mathrm{Cr}$ content let the $\mathrm{TaC}$ fraction stationary but it favors the formation of more chromium carbides than for $30 \mathrm{wt} . \% \mathrm{Cr}$. One can suspect a solid solution effect in a first time (sufficient available place for the greatest part of chromium and tantalum in the NCT10Cr alloy) and thereafter new balance between solid solution and carbides when $\mathrm{Cr}$ is more present in the chemical composition, with a singular effect in the case of the NCT30Cr alloy in which the chromium tends to stay preferentially in solid solution and to promote the formation of more TaC carbides.

Concerning the oxidation point of view, one can start by reminding that it was earlier observed that the Ni-30Cr-0.4C-6Ta alloy, serving as base for this work, was well oxidation resistant at high temperature. However one must also remind that it presented a high tendency to oxide spallation in thermal cycling. Concerning the strengthening particles for potential high temperature mechanical properties, this alloy presented the problem of co-precipitation of primary tantalum carbides and chromium carbides, despite that the weight contents in $\mathrm{C}$ and $\mathrm{Ta}$ were chosen to obtain equal atomic contents for these two carbide-forming elements. This molar equivalence of $\mathrm{Ta}$ and $\mathrm{C}$ was a recipe which was nonetheless efficient for cobalt-based and ironbased alloys. Thanks to its good behavior in isothermal oxidation it was permitted to envisage to 
decrease the $\mathrm{Cr}$ content in order to promote the precipitation of more $\mathrm{TaC}$ at the expense of the chromium carbides.

In these alloys, chromium is the most important element for the high temperature oxidation behavior. Its content was here either too low to allow good resistance (the $10 \mathrm{wt} . \% \mathrm{Cr}$ contained in the NCT10Cr alloy), or sufficiently high (30wt.\% and beyond). The $20 \mathrm{wt} . \% \mathrm{Cr}-$ containing alloy (NCT20Cr) seems to well behave at the two test temperatures but it is possible that this behavior may degenerate for durations higher than 20 hours. This is suggested by the not perfect compactness and regularity of the chromia scale: after 24 hours at 1127 or $1237^{\circ} \mathrm{C}$ this chromia scale contains porosities and is a little wavy because of the possible start of inward oxidation. It is possible that this wavy shape of the external chromia scale favored its adherence on the substrate. Indeed the chromia scale had much less spalled off than for the Cr-richer alloys. Concerning spallation, only the alloys with irregular alloy/oxide scale interface were resistant against this phenomenon during cooling. Indeed the NCT30Cr, NCT40Cr and NCT50Cr all lost the main part of their external oxides. It was thought earlier [21] that tantalum oxide which formed just under the chromia scale may threaten the adherence of chromia on substrate. This was found again here for the alloys containing between 30 and $50 \mathrm{wt} . \% \mathrm{Cr}$ which displayed both a very regular alloy/oxide scale interface and an almost continuous sub-oxide of $\mathrm{CrTaO}_{4}$. The deleterious effect of the $\mathrm{CrTaO}_{4}$ sub-layer on the adherence of chromia may be explained by the mismatch of crystalline network between chromia (eskolaite) which possesses a corundum crystal structure (with $\mathrm{Cr}^{\mathrm{III}}$ replacing $\mathrm{Al}^{\mathrm{III}}$ at the same locations in the crystal) and the rutile structure of $\mathrm{CrTaO}_{4}[24,25]$. Classically encountered in case of high Ta contents (5 to 9 wt.\%) in polycrystalline [26], directionally solidified [27] and single-crystalline [28] nickel-based superalloys, it was reported that tantalum often leads to the formation of more or less continuous sub-layers of $\mathrm{CrTaO}_{4}$ during high temperature oxidation. This starts rather early and progresses with the growth or coarsening of the subsurface $\mathrm{CrTaO}_{4}$ islands together with the deepening of the $\mathrm{TaC}$-free zone. The coalescence of these coarsening subsurface oxides progressively results in an almost continuous $\mathrm{CrTaO}_{4}$ sub-layer. Consequently to the formation of this oxide of both chromium and tantalum, severe spallation of the chromia external scale during post-oxidation cooling was systematically observed for Ta-rich nickel-based, cobalt-based, iron-based and \{iron, nickel\}-based polycrystalline cast alloys [30-32].

In all cases $\mathrm{Cr}$ diffused towards the oxidation front, from the solid solution matrix, the dissolving chromium carbides or the disappearing BCC Cr-phase. The two latter acted as important Cr-reservoirs, depending on the alloy. Tantalum diffused too from the solid solution matrix and from the tantalum carbides which are important Ta-reservoirs too. One well knows the consequence for chromium: formation and maintenance of a protective chromia-scale. Contrariwise, for Ta and its oxide, one does not know if its formation, obviously detrimental for the adherence of the external oxide, may act as a supplementary protection against oxidation, added to the one by chromia. It is true that the NCT10Cr alloy, although threatened here and there by a possible local catastrophic oxidation, rather resisted oxidation even at $1237^{\circ} \mathrm{C}$, perhaps helped by the subsurface continuous $\mathrm{CrTaO}_{4}$ oxide. This merits to be deeper studied. Solutions for combatting the oxide spallation problem must be found, why not by an yttrium addition allowing the pegging of the external scale. 


\section{CONCLUSION}

Decreasing the $\mathrm{Cr}$ content of the Ni-30Cr-O.4C-6Ta base (wt.\%) induced a visible lowering of the oxidation resistance at the two studied temperatures as soon as the alloy contains only $10 \mathrm{wt} . \% \mathrm{Cr}$. But the oxidation was not catastrophic of a general manner, at least after 24 hours of exposure to air. It is possible that Ta was responsible of the limitation of the detrimental effect of the Cr lowering down to a so low content. But this $\mathrm{Cr}$ decrease did not induced the expected effect, as is to say the stabilization of the TaC carbides known to be very favorable to mechanical strength at elevated temperature. Curiously, but a possible explanation was presented here, this is by increasing the $\mathrm{Cr}$ content that one obtains more $\mathrm{TaC}$ carbides with few chromium carbides. Since this effect was accompanied by a better resistance against high temperature isothermal oxidation, the way to follow is progressively increasing the $\mathrm{Cr}$ content beyond the usual $30 \mathrm{wt} . \% \mathrm{Cr}$, but not too high to avoid the appearance of the BCC-Cr phase which can be supposed to mechanically weaken the alloy. The optimal $\mathrm{Cr}$ content remains to be found, and the oxidation and creep behaviors to be specified.

\section{References}

1. P. Kofstad, High Temperature Corrosion, Elsevier Applied Science, 1988.

2. D. Young, High Temperature and Corrosion of Metals, Elsevier, 2008.

3. C. T. Sims, W. C. Hagel, The Superalloys, John Wiley and Sons, 1972.

4. E. F. Bradley, Superalloys: A technical guide, Metals Park: ASM International, 1988.

5. N. Birks, G. H. Meier, F. S. Pettit, Introduction to the High-Temperature Oxidation of Metals $2^{\text {nd }}$ ed., Cambridge University Press, 2009.

6. S. Langard, Biological and Environmental Aspects of Chromium, Elsevier Science, 1983.

7. D. Caplan, M. Cohen, Journal of the Electrochemical Society, 108(5), 438 (1961).

8. P. Berthod, Oxidation of Metals, 64(3-4), 235 (2005).

9. G. C. Wood, I. G. Wright, T. Hodgkiess, D. P. Whittle, Werkstoffe und Korrosion, 21, 900 (1970).

10. N. Mu, K. Jung, N. M. Yanar, F. S. Pettit, G. R. Holcomb, B. H. Howard, G. H. Meier, Oxidation of Metals, 79, 461 (2013).

11. G. R Holcomb, D. E. Halman, Scripta Metarialia, 54, 1821 (2006).

12. S. R. J. Saunders, M. Monteiro, F. Rizzo, Progress in Materials Science 53, 775 (2008).

13. P. Berthod, L. Aranda, S. Mathieu, M. Vilasi, Oxidation of Metals, 79(5-6), 517 (2013).

14. P. Berthod, L. Aranda, C. Vébert, S. Michon, Calphad, 28(2), 159 (2004).

15. M. J. Donachie, S. J. Donachie, Superalloys: A Technical Guide ( $2^{\text {nd }}$ Edition), Materials Park: ASM International, 2002.

16. S. Michon, L. Aranda, P. Berthod, P. Steinmetz, La Revue de Métallurgie - C.I.T. I Science et Génie des Matériaux, 9, 651 (2004).

17. P. Berthod, Advanced Materials Letters, 8(8), 866 (2017).

18. P. Berthod, Advances in Materials Science and Engineering, article ID 4145369, https://doi.org/10.1155/2017/4145369 (2017).

19. L. Corona, E. Conrath, P. Berthod, M. Ritouet, proceedings of the International Conference on Sustainable Energy and Information Engineering (SEEIE 2016) 442-446. 
20. J. Di Martino, S. Michon, L. Aranda, P. Berthod, R. Podor, C. Rapin, Annales de Chimie - Sciences des Matériaux, 28 (Suppl. 1), S231 (2003).

21. P. Berthod, C. Vébert, L. Aranda, Journal of Materials Science 42, 352 (2007).

22. E. Conrath, P. Berthod, Materials at High Temperature 33(2), 189 (2016).

23. H.-T. Lin, J. Hemrick, M. Singh, A. Michaelis, Advanced and Refractory Ceramics for Energy Conservation and Efficiency, John Wiley and Sons, 2015.

24. P. Massard, J.-C. Bernier, A. Michel, Journal of Solid State Chemistry, 4, 269 (1972).

25. M.A. Tena, M. Llusar, J.-A. Badenes, M. Vicente, G. Monros, British Ceramic Transactions, 99(5), 219 (2000).

26. S.-J. Park, S.-M. Seo, Y.-S. Yoo, H.-W. Jeong, H. Jang, Corrosion Science 90, 305 (2015).

27. W. Ren, F. Ouyang, B. Ding, Y. Zhong, J. Yu, Z. Ren, L. Zhou, Journal of Alloys and Compounds, 724, 565 (2017).

28. J. A. Nychka, D. R. Clarke, G. H. Meier, Materials Science and Engineering A, 490, 359 (2008).

29. P. Berthod, S. Raude, A. Chiaravalle, A.-S. Renck, C. Rapin, R. Podor, La Revue de Métallurgie - C.I.T./Science et Génie des Matériaux, 12, 1031 (2004).

30. P. Berthod, L. Aranda, C. Vébert, Annales de Chimie-Science des Matériaux, 31(2), 213 (2006).

31. P. Berthod, S. Raude, A. Chiaravalle, Annales de Chimie-Science des Matériaux, 31(2), 237 (2006).

32. P. Berthod, Y. Hamini, L. Aranda, Materials Science Forum, 595-598, 861 (2008). 
TABLE 1. Theoretic compositions for the five studied alloys (weight contents).

\begin{tabular}{|c|c|c|c|c|}
\hline Alloys & $\mathrm{Ni}$ & $\mathrm{Cr}$ & $\mathrm{Ta}$ & $\mathrm{C}$ \\
\hline "NCT10Cr" & Bal. & 10 & 6 & 0.4 \\
\hline "NCT20Cr" & Bal. & 20 & 6 & 0.4 \\
\hline "NCT30Cr" & Bal. & 30 & 6 & 0.4 \\
\hline "NCT40Cr" & Bal. & 40 & 6 & 0.4 \\
\hline "NCT50Cr" & Bal. & 50 & 6 & 0.4 \\
\hline
\end{tabular}

TABLE 2. Obtained chemical compositions for the five alloys (weight contents, 3 EDS full frame analyses).

\begin{tabular}{|c|c|c|c|c|}
\hline Alloys & $\mathrm{Ni}$ & $\mathrm{Cr}$ & $\mathrm{Ta}$ & $\mathrm{C}^{*}$ \\
\hline "NCT10Cr" & Bal. & $10.2 \pm 0.3$ & $5.9 \pm 0.2$ & 0.4 \\
\hline "NCT20Cr" & Bal. & $19.8 \pm 0.2$ & $6.3 \pm 0.1$ & 0.4 \\
\hline "NCT30Cr" & Bal. & $27.2 \pm 0.5$ & $10.1 \pm 0.4$ & 0.4 \\
\hline "NCT40Cr" & Bal. & $40.3 \pm 0.6$ & $6.9 \pm 0.5$ & 0.4 \\
\hline "NCT50Cr" & Bal. & $49.6 \pm 0.6$ & $6.6 \pm 0.3$ & 0.4 \\
\hline
\end{tabular}

TABLE 3. Obtained chemical compositions for the matrix in the as-cast alloys (weight contents, 3 EDS spot analyses).

\begin{tabular}{|c|c|c|c|c|}
\hline Alloys & $\mathrm{Ni}$ & $\mathrm{Cr}$ & $\mathrm{Ta}$ & $\mathrm{C}$ \\
\hline "NCT10Cr" & Bal. & $10.0 \pm 0.2$ & $6.8 \pm 1.2$ & \\
\hline "NCT20Cr" & Bal. & $19.0 \pm 0.3$ & $4.6 \pm 0.2$ & \multirow{2}{*}{ Not } \\
\hline "NCT30Cr" & Bal. & $26.0 \pm 0.1$ & $6.4 \pm 0.3$ & measurable \\
\hline "NCT40Cr" & Bal. & $38.0 \pm 0.2$ & $3.8 \pm 0.3$ & \\
\hline \multirow{2}{*}{ "NCT50Cr" } & Grey matrix & $45.5 \pm 0.3$ & $3.8 \pm 0.1$ & \\
\cline { 2 - 4 } & Black matrix & $60.6 \pm 0.9$ & $3.1 \pm 0.4$ & \\
\hline
\end{tabular}

TABLE 4. Intervals of thickness values for the external oxide scale (first results column) and average \pm standard deviation values of the carbide-free depth (second results column) for the five alloys oxidized for $24 \mathrm{~h}$ at $1127^{\circ} \mathrm{C}$

\begin{tabular}{|c|c|c|}
\hline Alloys & Oxide scale thickness $(\mu \mathrm{m})$ & Carbide-free zone depth $(\mu \mathrm{m})$ \\
\hline "NCT10Cr" & $19-44$ & $66.0 \pm 9.0$ \\
\hline "NCT20Cr" & $7-20$ & $49.3 \pm 3.1$ \\
\hline "NCT30Cr" & Spalled off & $44.3 \pm 4.3$ \\
\hline "NCT40Cr" & Spalled off & $57.9 \pm 10.6$ \\
\hline "NCT50Cr" & Spalled off & $34.2 \pm 4.9$ \\
\hline
\end{tabular}


TABLE 5. Average and standard deviation for the chromium content in alloy close to the interface with the external oxide (3 EDS spot analyses)

\begin{tabular}{|c|c|c|}
\hline $\begin{array}{c}\text { Alloys } \\
\left(24 \mathrm{~h} 1127^{\circ} \mathrm{C}\right)\end{array}$ & $\begin{array}{c}\text { Chromium content in extreme } \\
\text { surface (wt.\%) }\end{array}$ & $\begin{array}{c}\text { Difference to the initial Cr content } \\
\text { (wt. \%) }\end{array}$ \\
\hline "NCT10Cr" & $4.8 \pm 0.3$ & -5.4 \\
\hline "NCT20Cr" & $15.5 \pm 1.3$ & -4.3 \\
\hline "NCT30Cr" & $21.6 \pm 0.1$ & -5.6 \\
\hline "NCT40Cr" & $33.2 \pm 0.1$ & -7.1 \\
\hline "NCT50Cr" & $41.1 \pm 1.1$ & -8.5 \\
\hline
\end{tabular}

TABLE 6. Intervals of thickness values for the external oxide scale (first results column) and average \pm standard deviation values of the carbide-free depth (second results column) for the five alloys oxidized for $24 \mathrm{~h}$ at $1237^{\circ} \mathrm{C}$

\begin{tabular}{|c|c|c|}
\hline Alloys & Oxide scale thickness $(\mu \mathrm{m})$ & Carbide-free zone depth $(\mu \mathrm{m})$ \\
\hline "NCT10Cr" & $17-160$ & $>300$ \\
\hline "NCT20Cr" & $11-15$ & $105 \pm 5$ \\
\hline "NCT30Cr" & Spalled off & $87 \pm 6$ \\
\hline "NCT40Cr" & Spalled off & $170 \pm 13$ \\
\hline "NCT50Cr" & Spalled off & $101 \pm 6$ \\
\hline
\end{tabular}

TABLE 7. Average and standard deviation for the chromium content in alloy close to the interface with the external oxide (3 EDS spot analyses)

\begin{tabular}{|c|c|c|}
\hline $\begin{array}{c}\text { Alloys } \\
\left(24 \mathrm{~h} 1237^{\circ} \mathrm{C}\right)\end{array}$ & $\begin{array}{c}\text { Chromium content in extreme } \\
\text { surface (wt.\%) }\end{array}$ & $\begin{array}{c}\text { Difference to the initial Cr content } \\
(\mathrm{wt} . \%)\end{array}$ \\
\hline "NCT10Cr" & $4.1 \pm 0.2$ & -6.1 \\
\hline "NCT20Cr" & $14.5 \pm 0.3$ & -5.3 \\
\hline "NCT30Cr" & $21.5 \pm 0.2$ & -5.7 \\
\hline "NCT40Cr" & $33.7 \pm 0.1$ & -6.6 \\
\hline "NCT50Cr" & $42.7 \pm 1.1$ & -6.9 \\
\hline
\end{tabular}




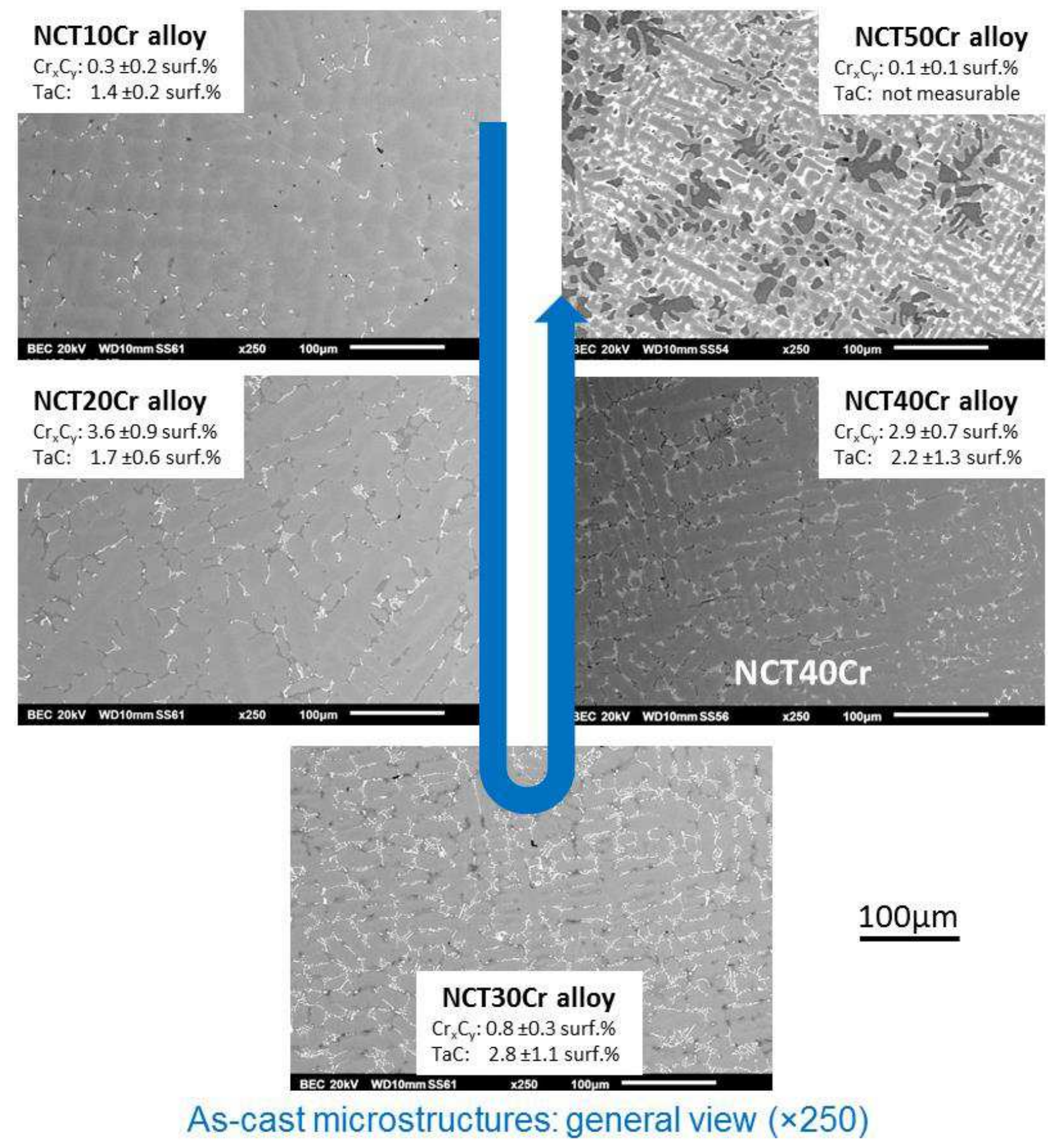

FIGURE 1. As-cast microstructures of the five studied alloys (SEM/BSE micrographs, large view: $\times 250$ ) 


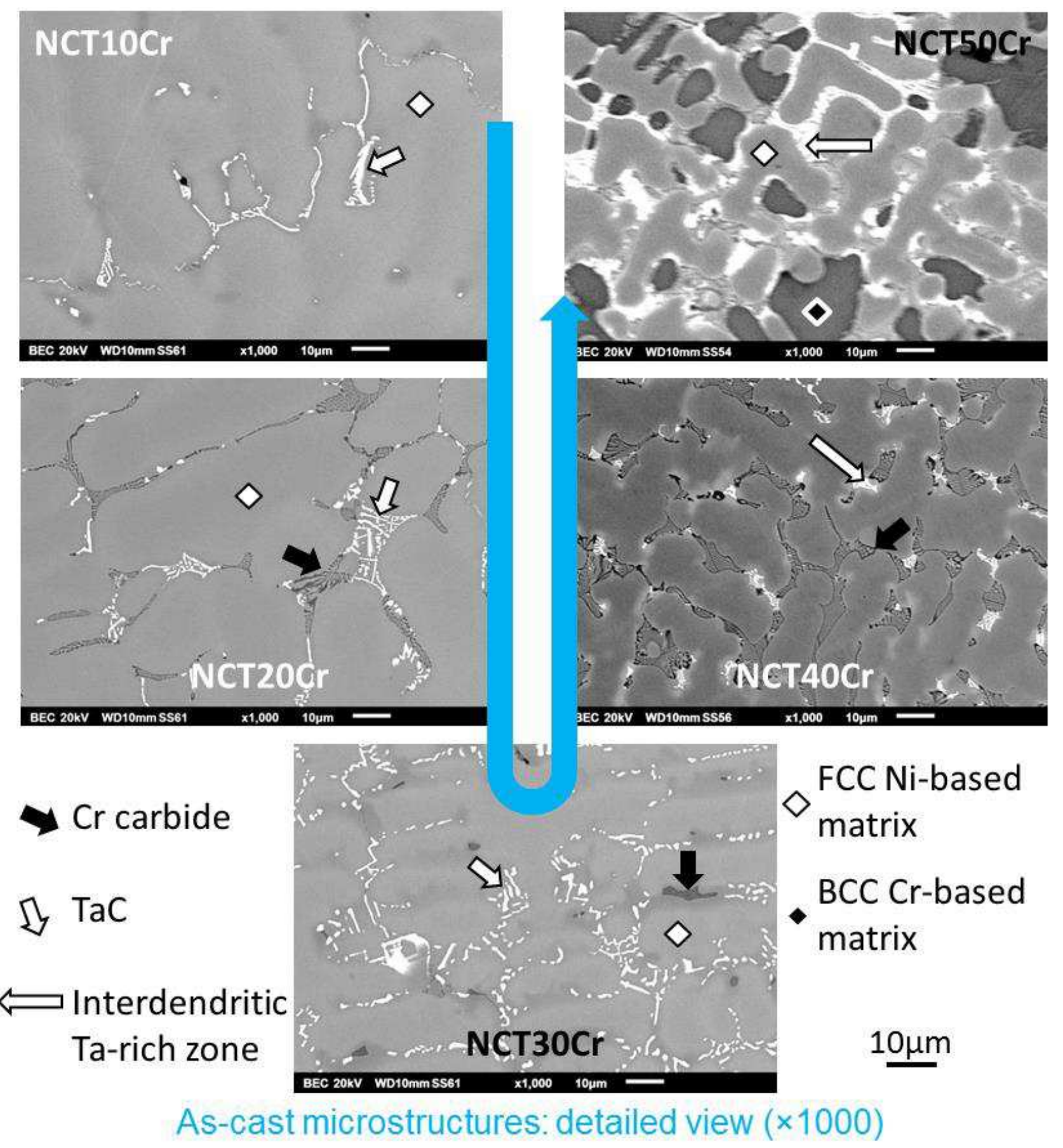

FIGURE 2. As-cast microstructures of the five studied alloys (SEM/BSE micrographs, detailed view, $\times 1000)$ 


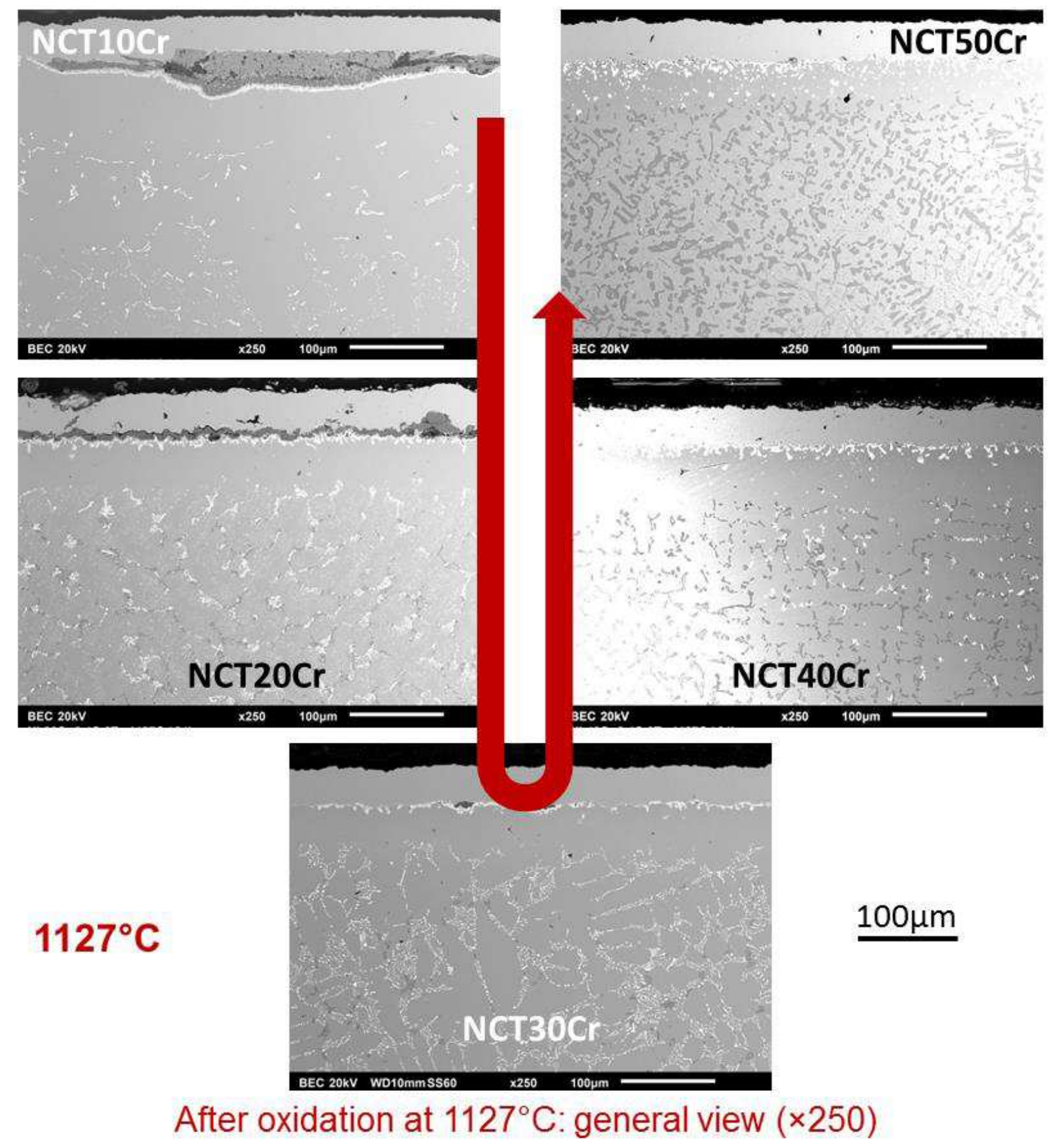

FIGURE 3. Surface and subsurface states after oxidation at $1127^{\circ} \mathrm{C}$ during $24 \mathrm{~h}$ $($ SEM/BSE micrographs, large view: $\times 250)$ 


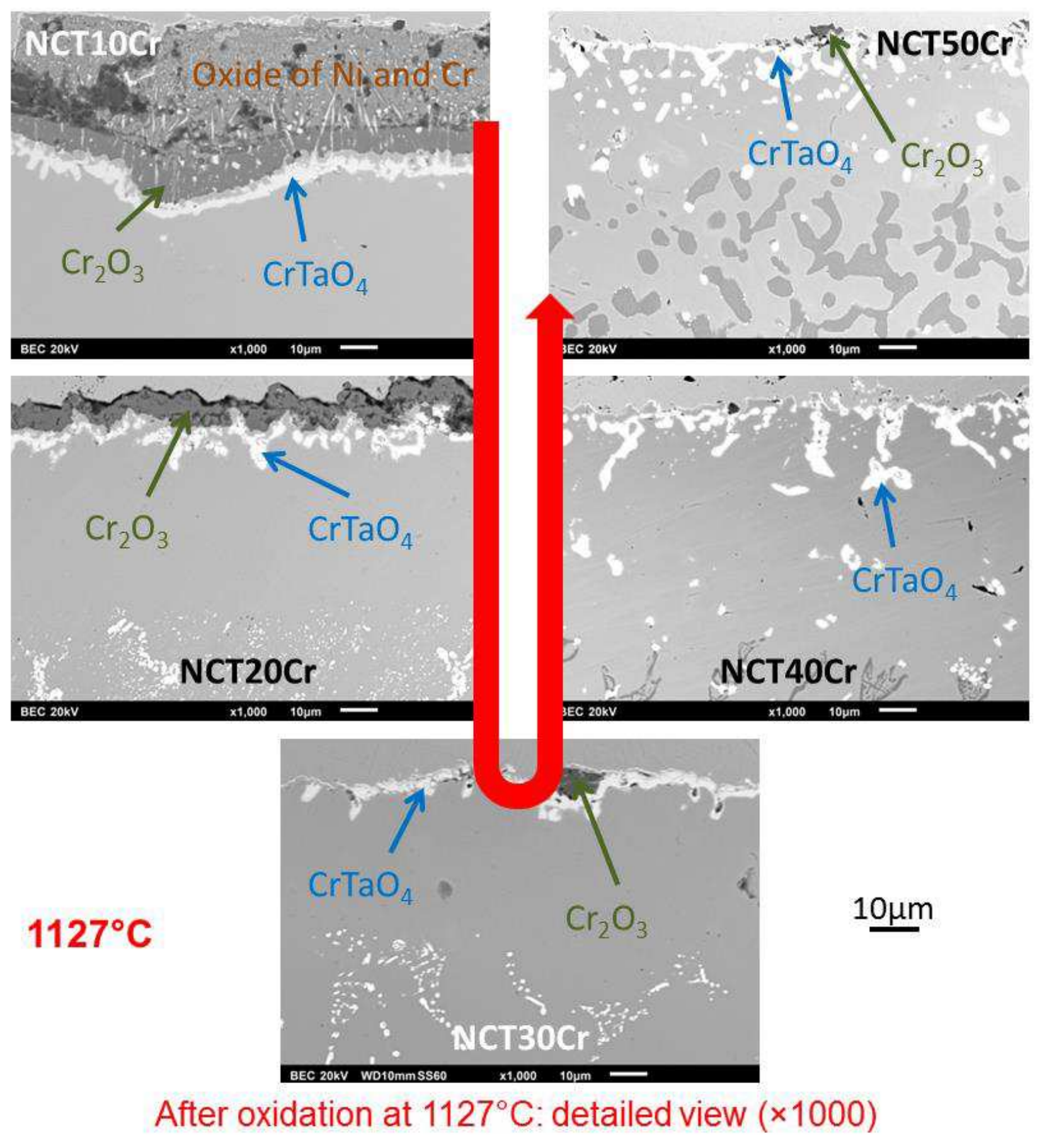

FIGURE 4. Surface and subsurface states after oxidation at $1127^{\circ} \mathrm{C}$ during $24 \mathrm{~h}$ (SEM/BSE micrographs, detailed view: $\times 1000)$ 

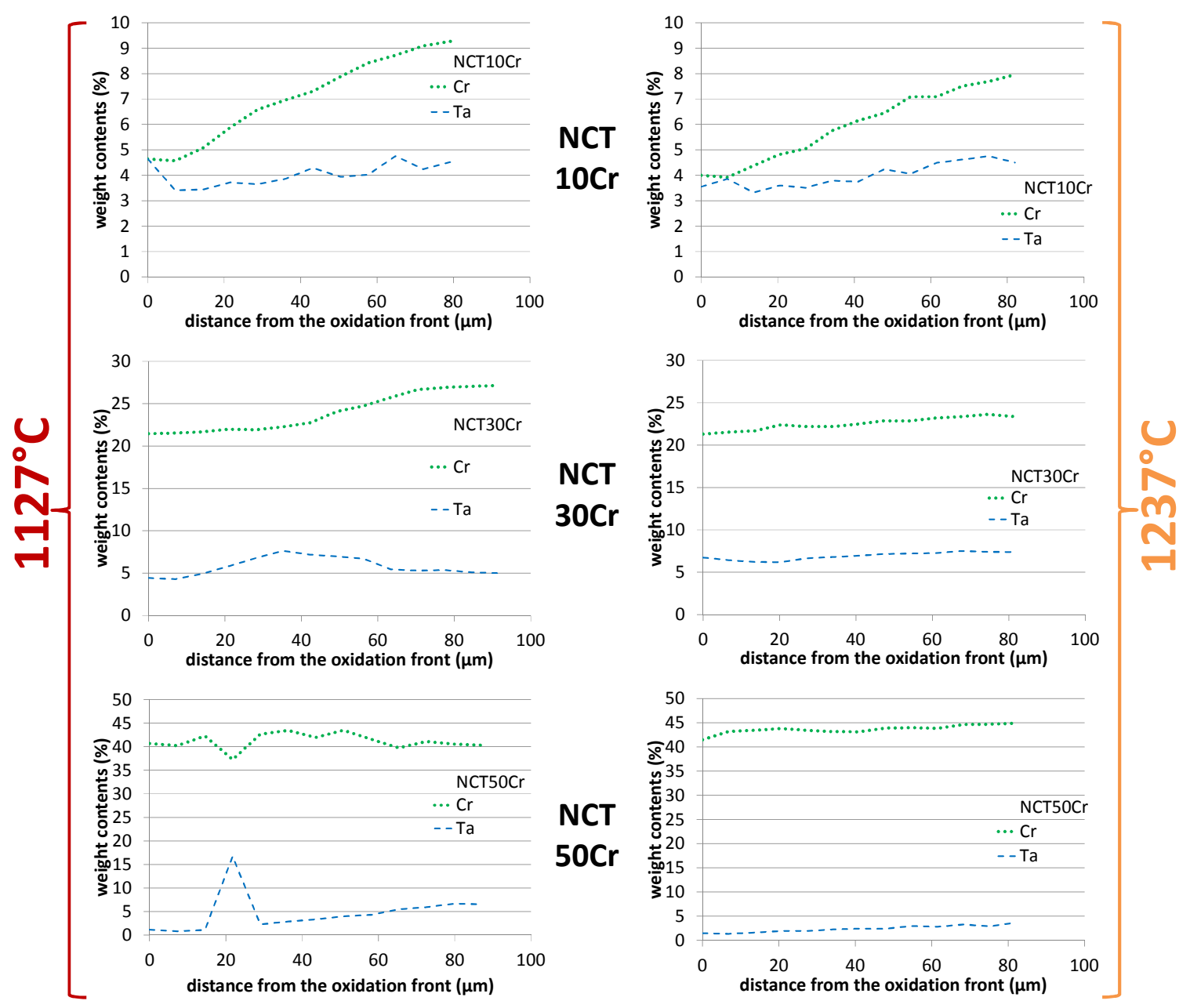

FIGURE 5. Concentration profiles in the subsurfaces of three of the five alloys after oxidation at $1127^{\circ} \mathrm{C}$ and at $1237^{\circ} \mathrm{C}(\mathrm{SEM} / \mathrm{EDS})$ 


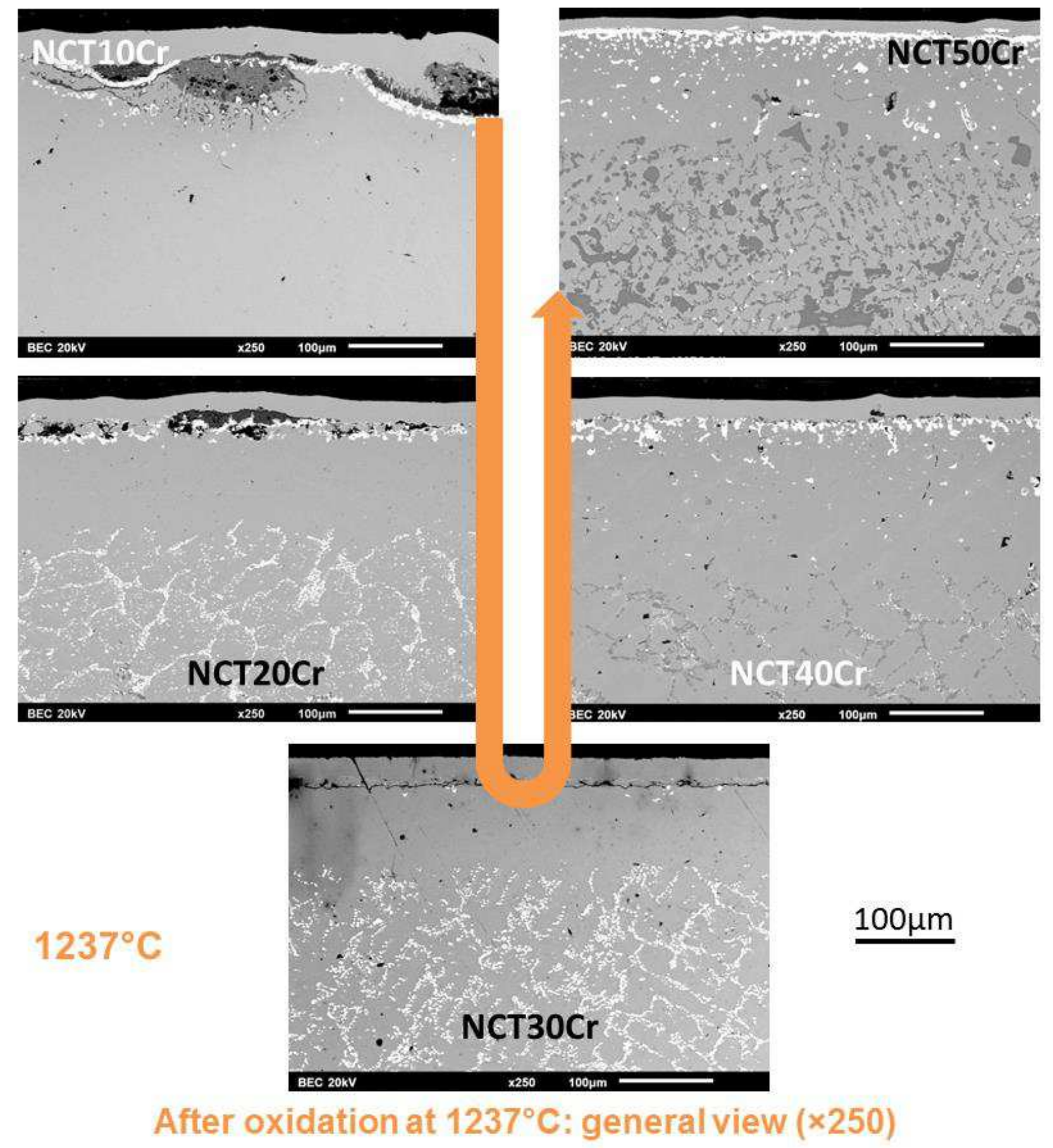

FIGURE 6. Surface and subsurface states after oxidation at $1237^{\circ} \mathrm{C}$ during $24 \mathrm{~h}$ (SEM/BSE micrographs, large view: $\times 250)$ 


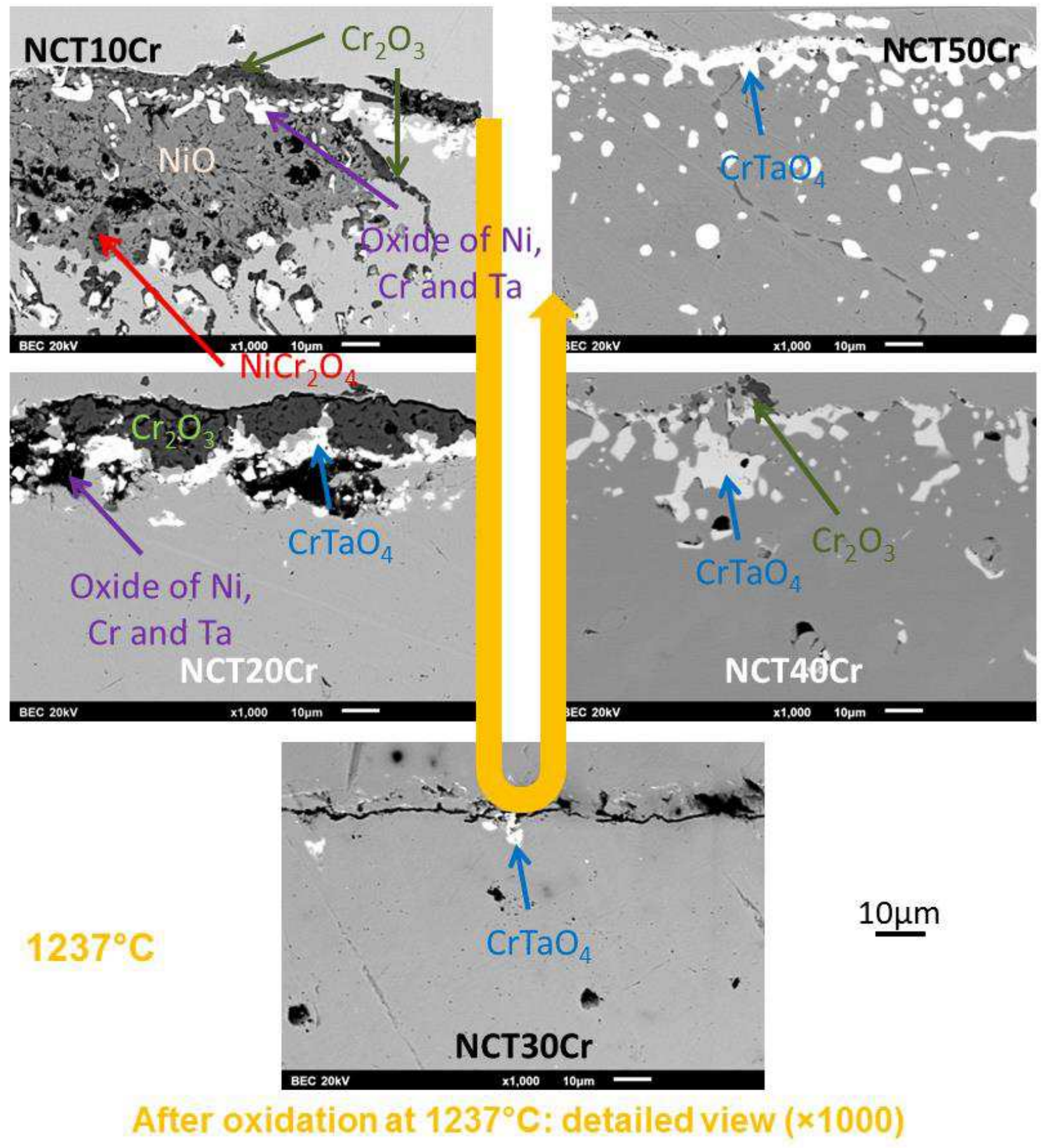

FIGURE 7. Surface and subsurface states after oxidation at $1237^{\circ} \mathrm{C}$ during $24 \mathrm{~h}$ (SEM/BSE micrographs, detailed view: $\times 1000)$ 


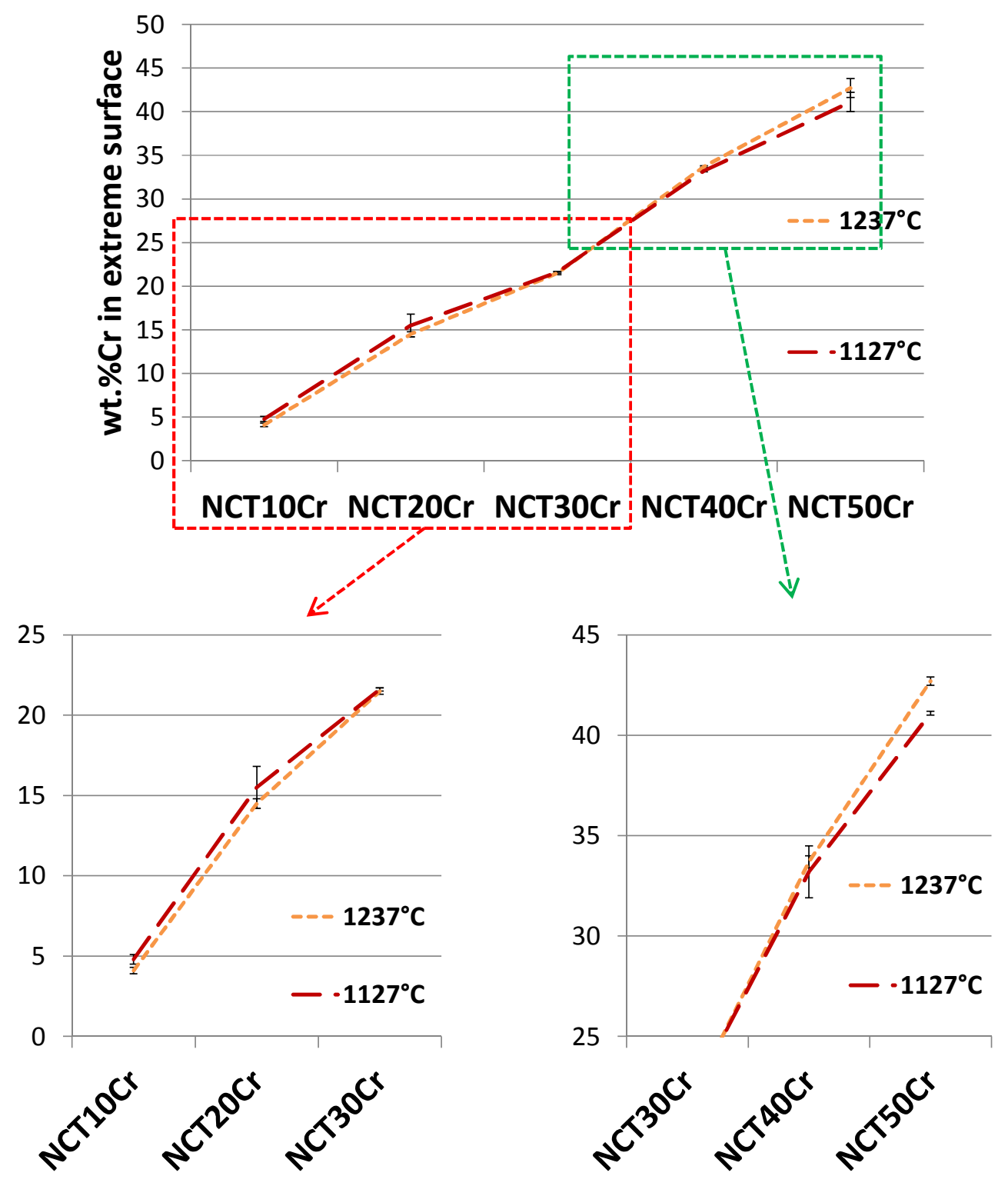

FIGURE 8. Comparison between the chromium content in extreme surface after $24 \mathrm{~h}$ of oxidation at $1127^{\circ} \mathrm{C}$ and at $1237^{\circ} \mathrm{C}$ (SEM/EDS) 